\title{
Scholarly Personal Narrative: Storied Forms as Teaching, Learning, and Writing
}

Marcea Ingersoll

\begin{abstract}
By embedding narrative theory within the practice of storied forms, there can be pedagogical movement from difficulty to insight. This piece explores scholarly personal narrative as a creative and critical method for attaining academic understanding. The ideas of three narrative scholars (Nash, Fowler, and Luce-Kapler) surface within two writing forms-a letter and a poem. The author playfully reports on the powerful processes that are engaged when shared creative story forms become part of teaching, learning, and writing.
\end{abstract}

Dear Robert (Nash, 2004):

You don't know me, but I've spent quite a bit of time with you. Well, not with you per se, but with your words and ideas. We first met when I was in graduate school, enrolled in a course on scholarly personal narrative. You wouldn't remember it, of course, but Rebecca Luce-Kapler introduced us. I knew right away that you were someone who would become, as Leah Fowler would say, a friend in my intellectual living room. If you haven't met Rebecca and Leah already, they also share your ideas about narrative as a way of making deep connections. (You'll find more information on them, below.)

Anyway, Robert (do you mind if I call you Robert?), when we were introduced, I learned why personal narrative writing is important to educators, and that you were not wrong when you suggested that it can also result in "stunning self-insights." Adopting this perspective has been influential to my own teaching and writing, and I share your conviction that, "all kinds of writing-personal narrative writing in particular_can reach, and even surpass, a professional school's highest scholarly standards." Wow, you weren't kidding when you said that first-person narratives were the ones that pushed your students the hardest and required more creativity and candor than typical research papers or literature reviews. Do you remember saying all that? (It was all right there at the beginning, on page three actually, of your book.)

Let me tell you, when I wrote my first scholarly narrative, I had never struggled to write a paper the way I struggled to write that one. Hours and hours of sitting and staring at the computer. Of reading and rereading and attempting to paraphrase, simplify, analyze, draw connections between. Be creative yet thorough. It was an exercise in frustration unlike any other writing I had done before. And I couldn't quite figure out why. 
Honestly, Robert, it was such a struggle I decided to ask for an extension. Panic had set it. Determined to figure out what this was about, I sought solace in my classmates. (Okay I might have been procrastinating a bit, but I needed to know whether they were feeling this way, too.) It was time to get folks from the class together, have coffee, and figure out what on earth was going on. So, I emailed everyone to share my panic. And procrastinate. Everyone was willing. The very next afternoon at a downtown coffee shop we sat in brown chairs with steaming mugs, and AHA! it came out during our gathering that I wasn't the only one who had to ask for an extension.

In fact, many of us had. We were simultaneously relieved to find that we were not alone and perplexed by the commonality of the struggle. After all, we had just spent an entire semester on scholarly writing: we had analyzed our processes on other pieces, gained insight into when we wrote well and how we wrote best. We had done the readings. We couldn't figure out why everyone had such trouble when it came to writing our own scholarly narratives. (Well, not everyone. Here's a little bit of what happened at the coffee shop. I'm going to switch up the tense just to keep it interesting.)

Classmate one: I've submitted mine.

And conversation stops. Coffee cups are grasped. There is a collective leaning forward.

A shared intake of breath. A resonant pause over our croissants.

Classmate one: But it's only three pages.

The tension breaks.

Classmate two, most earnestly: Single spaced or double??

We laugh at the quintessentially academic clarification and then the confessions start.

And I'm overwhelmed by the sheepish acknowledgments, the bewilderment that it was such a difficult paper to write. We share our shame of having to ask for an extension, of feeling like our writing is directionless. Amateur. People seem astonished that I asked for an extension as well — they imagined I had submitted my paper ages ago—didn't think I'd still be struggling to find my way. Classmate three, looking right at me: I thought it would be easy for you.

So why wasn't it easy for me, Robert?

After all, I was quite accustomed to writing rather well rather quickly. My process for academic writing could be described as relatively straightforward. I get an idea, I make a plan, I do the reading. I make notes, I read a lot more than I plan to because there is just so much interesting stuff to read along the way, and sometimes I'Il veer off on a path I hadn't anticipated. But the journey usually goes according to plan and the destination I reach is the one plotted at the start; habitually, there are only minor detours along the way.

So why, Robert, was scholarly personal narrative so different?

Why? Why...

Here's what I think. Academic writing used to be easy for me because it allowed me to not be me. Scholarly writing used to be the donning of a robe, the settling into another skin, the freedom to mimic a voice of authority that came from without. Scholarly personal narrative is difficult because it must come from within. 
I had to write myself out of that difficulty and write myself into the academy.

There it is. That's why.

Scholarly narrative means knowing that scholarship is being responsible not merely for the synthesis, but also for the production of ideas. In your own voice.

So, Robert, all to say that I'm very grateful. To you and to Rebecca and Leah. I should probably write to them now, too.

Yours sincerely,

Student, teacher, and writer of narratives.

P.S. I forgot to tell you I wrote a poem as part of my paper. I thought I'd share it with you here.

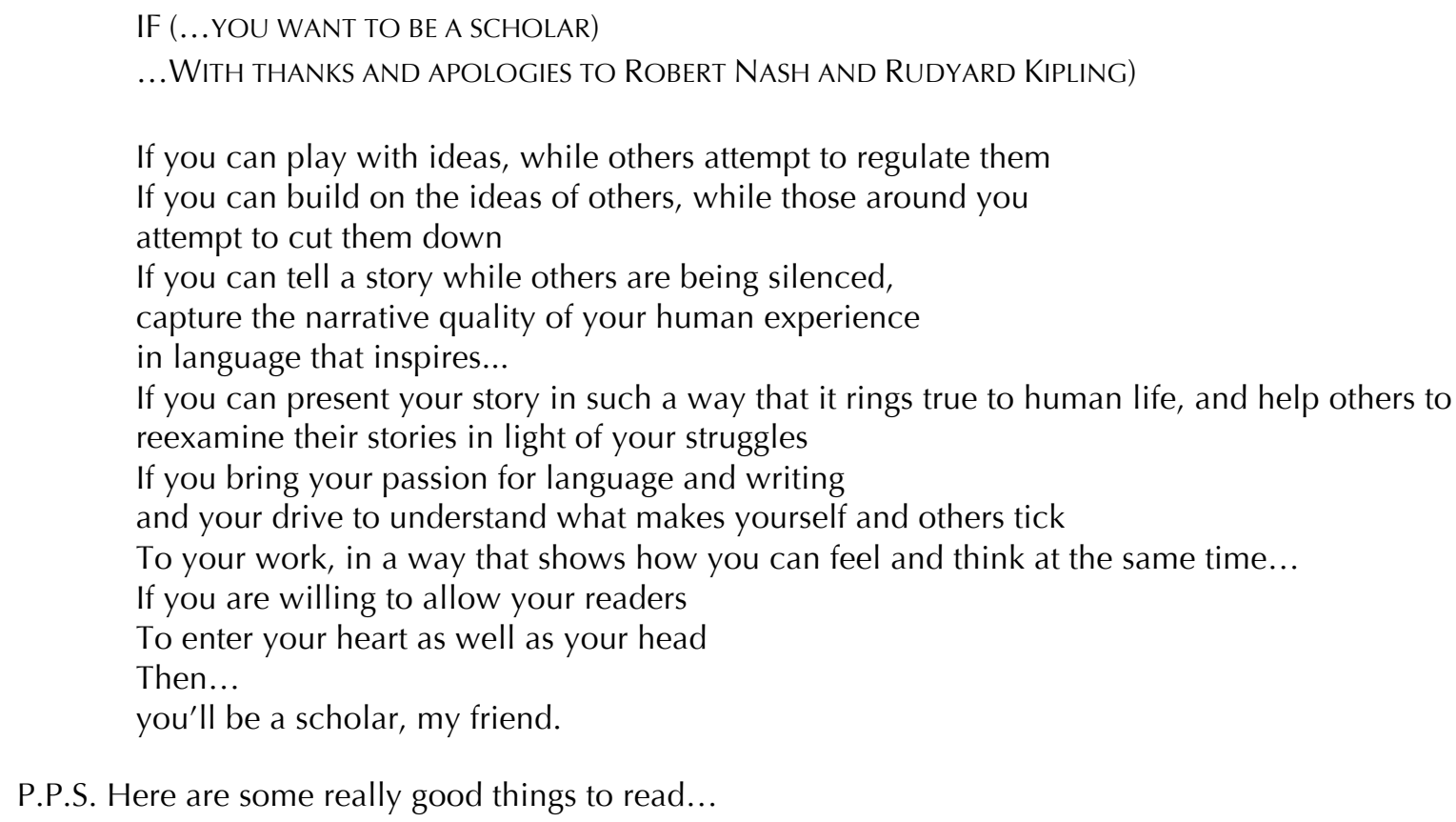

P.P.S. Here are some really good things to read...

\section{References}

Fowler, L. C. (2006). A curriculum of difficulty: Narrative research in education and the practice of teaching. New York, NY: Peter Lang.

Kipling, R. (1895). If. Retrieved from https://www.poetryfoundation.org/poems/46473/if---

Luce-Kapler, R. (2004). Writing with, through, and beyond the text: An ecology of language. New York, NY: Routledge.

Nash, R. J. (2004). Liberating scholarly writing: The power of personal narrative. New York, NY: Teachers College Press. 


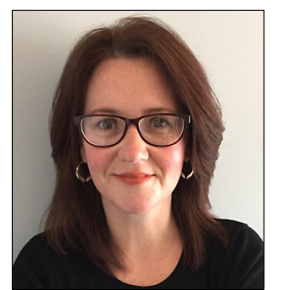

Marcea Ingersoll is a Maritimer by birth, a teacher by profession, and a global nomad by nature. In 2015, she became an Assistant Professor in the School of Education and a member of the Centre for Interdisciplinary Research on Narrative (CIRN) at St. Thomas University. Building on her experiences as an international teacher and teacher-educator, her scholarly work is situated at the crossroads of narrative, teacher education, and international teaching. Marcea is also interested in innovative pedagogical and methodological approaches to literacy practices at schools and in communities around the globe. 